\title{
Rancang Bangun Aplikasi Pencarian Mesjit Terdekat di Kota Medan
}

\author{
Siti Sundari ${ }^{1}$, Muhammad Al Hafis Nst $^{2}$,Haida Dafitri ${ }^{3}$ \\ Address : Universitas Harapan Medan, Fakultas Teknik dan Komputer, Program Studi Teknik Informatika, Indonesia
}

Email : Sundaristth@gmail.com, hafis.tes@gmail.com, aida.stth@gmail.com

${ }^{*}$ Corresponding Author

\begin{abstract}
Abstrak
SIG (System Information Geographic) memiliki kemampuan yang sangat baik dalam memvisualisasikan data spesial berikut atribut-atributnya. Kota Medan merupakan salah satu kota terbesar di wilayah Indonesia dalam hal fasilitas yang sudah dibangun terdapat berupa tempat beribadah disaat melakukan perjalanan jauh didaerah disekitar kota Medan. Brute Force adalah sebuah pendekatan langsung (straight forward) untuk memecahkan suatu masalah, yang biasanya didasarkan pada pernyataan masalah (problemstatement) dan definisi konsep yang dilibatkan. Brute force adalah sebuah pendekatan yang langsung (straightforward) untuk memecahkan suatu masalah, biasanya didasarkan pada pernyataan masalah (problem statement) dan definisi konsep yang dilibatkan. Algoritma brute force memecahkan masalah dengan sangat sederhana, langsung dan dengan cara yang jelas (obvious way).
\end{abstract}

Keywords - System Information Geografic, Kota Medan, Brute Force.

\section{Latar Belakang}

Untuk dapat mengetahui letak tempat peribadahan pada suatu kota terkadang sangat sulit, terlebih lagi bagi orang luar kota Medan, untuk mencari tempat ibadah bila sedang datang ke kota Medan, dan tidak mengetahui letak tempat ibadah saat waktunya untuk beribadah seperti sholat 5 waktu.

SIG (System Information Geographic) memiliki kemampuan yang sangat baik dalam memvisualisasikan data spesial berikut atribut-atributnya, memodifikasi bentuk, warna, ukuran dan simbol yang digabungkan untuk bisa memenuhi kebutuhan pengguna dalam mengakses informasi yang berhubungan dengan lokasi geografis wilayahnya, misalnya informasi jalan dan lokasi suatu fasilitas umum tempat beribadah.

Brute Force adalah sebuah pendekatan langsung (straight forward) untuk memecahkan suatu masalah, yang biasanya didasarkan pada pernyataan masalah (problemstatement) dan definisi konsep yang dilibatkan.

\section{Landasan Teori}

Adapun tahapan yang dilakukan untuk penyusunan tugas akhir ini yaitu :
1. Studi pustaka dengan mengumpulkan data - data dari berbagai sumber seperti buku referensi, majalah, internet, dan sumber - sumber lainnya.

2. Menganalisa permasalahan dan menyelesaikan dengan metode yang digunakan.

3. Praktik pembuatan program yang ingin dicapai.

4. Evaluasi dan koreksi terhadap penyusunan program.

5. Penyusunan laporan.

\subsection{Fasilitas Umum}

Fasilitas umum merupakan sebuah sarana yang dapat digunakan oleh siapa saja, oleh sebab itu sebuah fasilitas umum harus dapat memfasilitasi berbagai macam pengguna. Metode yang digunakan pada penelitian ini ialah pengamatan langsung dilapangan. serta pengumpulan dara sekunder mengenai permasalahan yang sama.

\subsection{Tempat Ibadah}

Pencarian tempat ibadah menjadi sangat penting ketika seseorang melakukan perjalanan. Ketika ingin menunaikan ibadah shalat, saat dalam perjalanan kita 
harus mengetahui letak dan posisi masjid terdekat. Kemudian juga akan pertimbangan fasilitas sarana dan prasarana gedung factor pendukung kegiatan ibadah [2]. Algoritma Brute Force adalah algoritma yang cocok untuk metode pencarian.

\subsection{Algoritma Brute Force}

Brute force adalah sebuah pendekatan yang langsung (straightforward) untuk memecahkan suatu masalah, biasanya didasarkan pada pernyataan masalah (problem statement) dan definisi konsep yang dilibatkan. Algoritma brute force memecahkan masalah dengan sangat sederhana, langsung dan dengan cara yang jelas (obvious way).

Dalam pembuatan sistem pencarian ini dibutuhkan algoritma sebagai proses berpikir pada komputer untuk melakukan pencarian yang cepat dan akurat, selain itu dalam pembuatan sistem pencarian ini penulis akan menggunakan algoritma brute force.

Search engine adalah situs-situs pada web yang didesain untuk menolong pengguna untuk mencari informasi yang tersimpan di situs-situs yang lain dan ibarat kendaraan yang kita gunakan dalam menjelajahi jagad raya didunia maya. Tanpa mesin pencari, kita hanya dapat mengandalkan alamat website yang spesifik dalam mengakses informasi yang dibutuhkan, itu pun jika kita memiliki alamat website. Hal tersebut akan membuat kita tidak dapat beranjak ke mana-mana dan tidak akan mengakses website apapun. [1]

\subsection{Geographic Information System ( GIS )}

GIS (Geographic Information System) atau sistem informasi berbasis pemetaan dan geografi adalah sebuah alat bantu manajemen berupa informasi berbantuan komputer yang berkait erat dengan sistem pemetaan dan analisis terhadap segala sesuatu serta peristiwaperistiwa yang terjadi di muka bumi. Komponen GIS adalah sistem komputer, data geospatial dan pengguna [3].

\section{Rancang dan Implementasi}

Perancangan sistem dan implementasi tentang pembuatan penerapan algoritma brute force untuk mencari lokasi masjid terdekat di kota medan berbasis android.

\subsection{Flowchart Program Aplikasi}

Bagian alir digunakan untuk alat bantu komunikasi dan untuk dokumentasi. Bagian ini menjelaskan urutan - urutan dari prosedur - prosedur yang ada di dalam sistem. Bagian alir sistem menunjukkan apa yang dikerjakan di sistem. Berikut ini

Program Studi Teknik Informatika

Universitas Prima Indonesia (UNPRI) Medan diagram flowchart mengikuti alir sistem kerja aplikasi, seperti gambar dibawah ini :

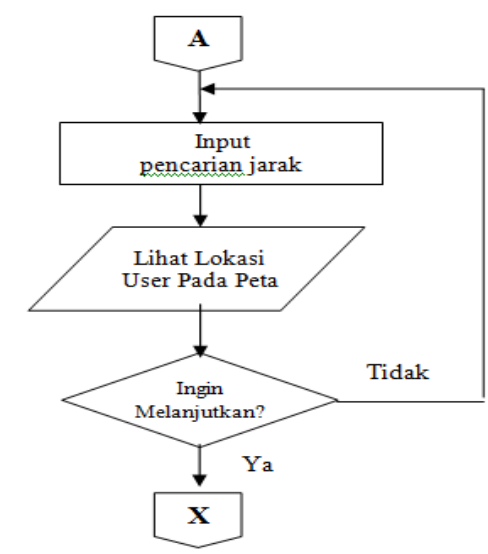

Gambar 1 Flowchart GPS

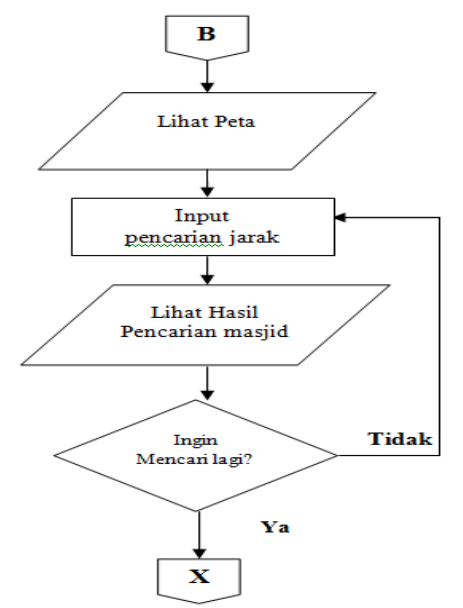

Gambar 2 Flowchart Pencarian Tempat Ibadah

\subsection{Flowchart program Aplikasi}

Tujuan dari percangan antarmuka pengguna adalah merancang interface yang efektif untuk sistem perangkat lunak. Pengguna sering menilai sistem dari interface, bukan dari fungsinya melainkan dari user interfacenya. Jika desain user interfacenya yang buruk, maka itu sering jadi alasannya untuk tidak menggunakan software.

Adapun tampilan rancangan login server dan client adalah seperti berikut :

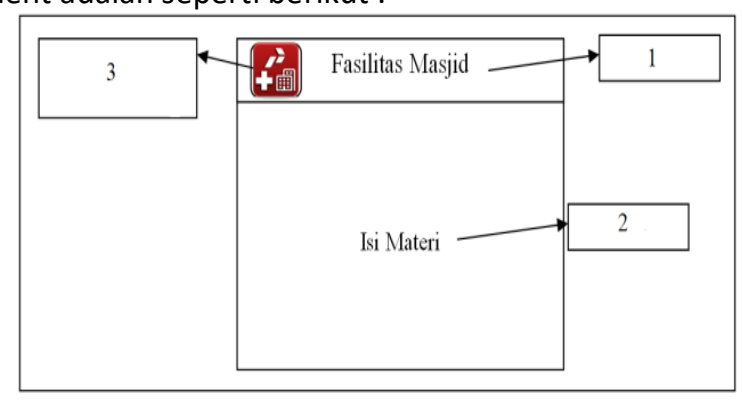

Gambar 3 Menu Utama 


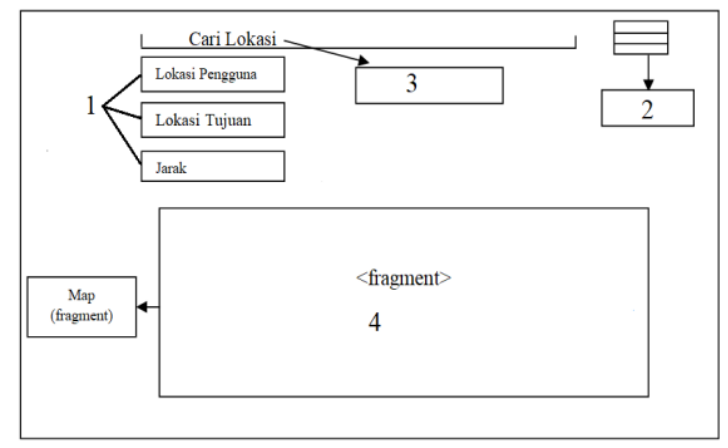

Gambar 4 Tampilan tempat ibadah

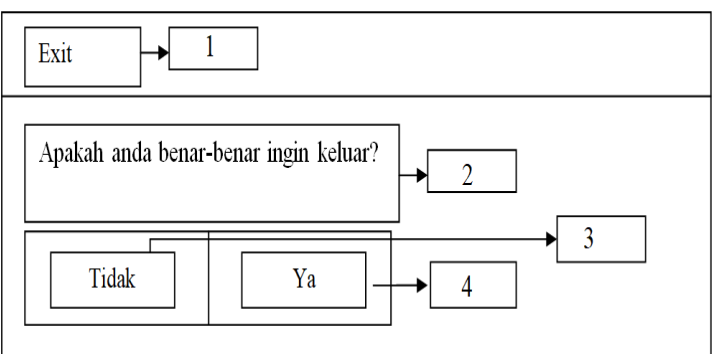

Gambar 5 Tampilan Keluar

\subsection{Implementasi}

Implementasi dari perangkat unak merupakan tahp terakhir dari proses pengembangan perangkat lunak setelah melalui tahapan perancangan. Berikut ini paparan implementasi dari perangkat lunak seperti gambar dibawah ini :

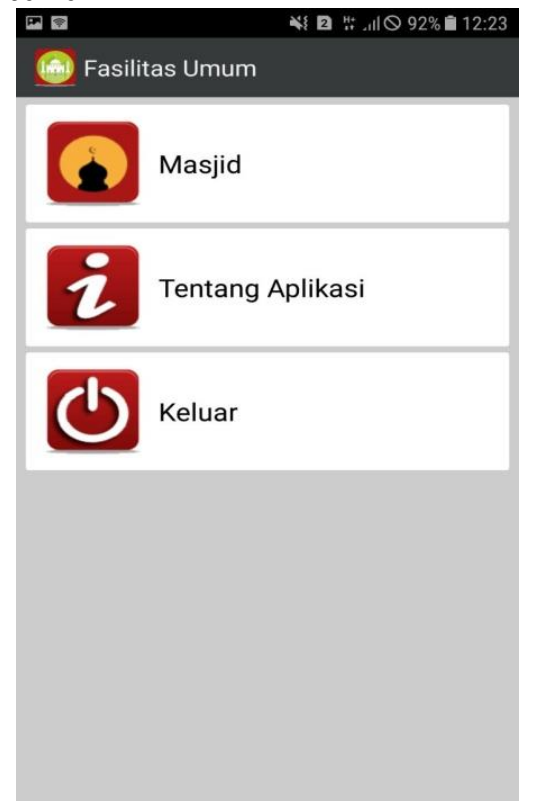

Gambar 6 Tampilan Menu Utama

Pada gambar 6 Pada keterangan sub-item menu pada aplikasi pengolahan citra adalah : Masjid merupakan menu masjid untuk mencari lokasi masjid terdekat dengan user agar user dapat melakukan ibadah tanpa harus mencari lokasi masjid yang jauh. Tentang aplikasi merupakan aplikasi menjelaskan cara kerja sistem yang telah disediakan oleh sistem, adapun informasi ini memberikan arahan pemakaian sistem aplikasi dan keterangan dari data diri penulis tugas akhir/perancang aplikasi sistem.

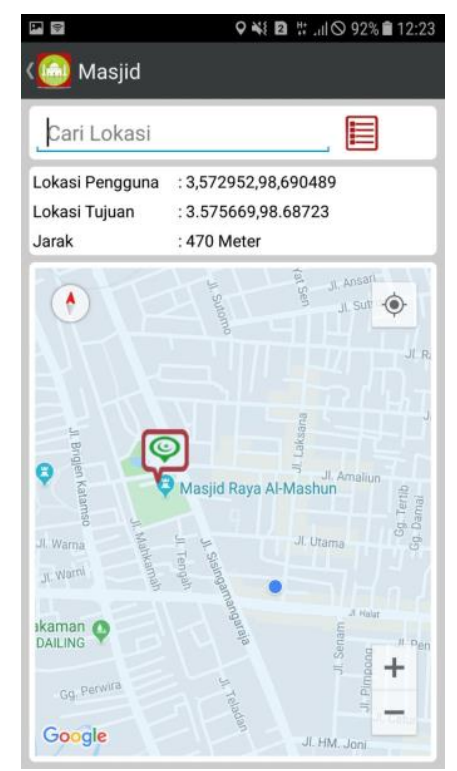

Gambar 7 Halaman Masjid

Pada gambar 7 peta lokasi untuk mencari lokasi fasilitas umum yang di inginkan dan melihat lokasi antara user dan tempat tujuan, serta jarak antara user dan lokasi tempat.

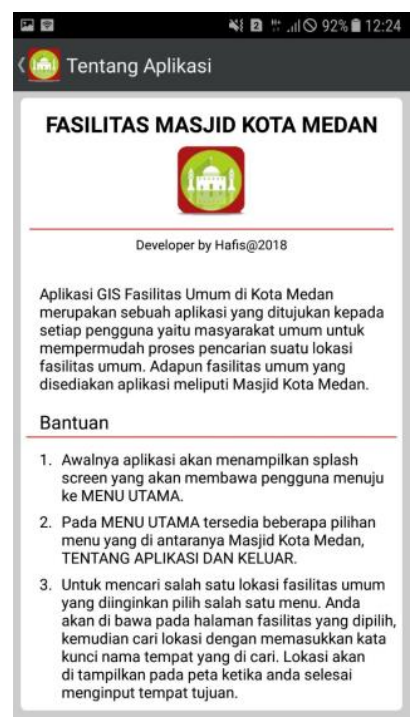

Gambar 8 Halaman Tentang

Pada gambar 8 menjelaskan bahwa nama pengguna, dan fasilitas umum yang dirancang sebagai 
penjelasan. Agar pengguna dapat mengerti dan memahami tata cara pengunaan aplikasi ini.

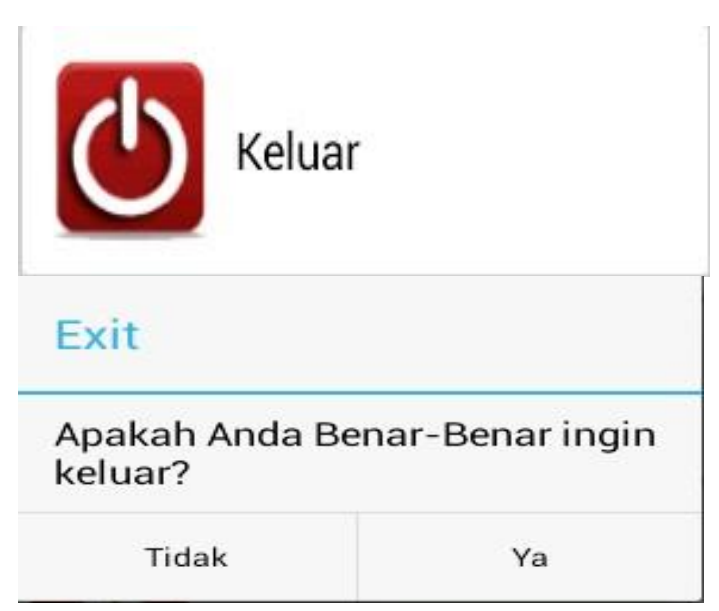

Gambar 9 Halaman Keluar

Pada gambar 9 menjelaskan bahwa terdapat tools untuk memberitahukan pengguna apabila ingin keluar dari aplikasi tersebut. Setelah menu keluar diklik maka akan keluar kotak dialog yang memberitahukan untuk keluar atau tidak.

\section{Kesimpulan}

Berikut ini kesimpulan dari aplikasi geografis system informasi kota Medan berbasis android yaitu :

1. Sistem aplikasi perangkat lunak yang dirancang untuk mencari dan menampilkan fasilitas umum berupa lokasi masjid terdekat yang ada di kota Medan.

2. Aplikasi perangkat lunak berupa eclipse berbasis android, memiliki kelebihan dalam perancangan suatu program peta lokasi berbasis geografis sistem informasi.

3. Aplikasi geografis informasi sistem ini memberikan kemudahan bagi masyarakat kota Medan dengan mudah mencari informasi fasilitas umum menggunakan internet melalui media android dimana pun berada dengan cepat sehingga masyarakat umum dapat terbantu untuk menemukan tempat yang di inginkan.

\section{Referensi}

[1] Bayu.2016."Implementasi Algoritma Brute Force Sebagai Mesin Pencari (Search Engine)Berbasis Web Pada Database". ISSN : 2088 - 1762 Vol. 6 No. 1 / Maret 2016.

[2] Kartiko. 2016. "Analisis Persebaran Tempat Ibadah Dan Kapasitasnya Berdasarkan Jumlah Penduduk Berbasis Sig" (Studi Kasus 5 Kecamatan di Kota Semarang).
[3] Prahasta,E. 2013. “Sistem Informatika Geografis: Konsep-konsep Dasar". Informatika, Bandung.

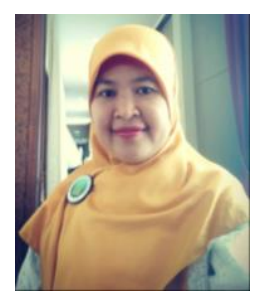

Haida Dafitri, ST, M.Kom Lahir di Medan, 17/05/1988. Pendidikan Strata1 (S1)Program Studi Teknik Informatika di Sekolah Tinggi Teknik Harapan Medan dan Strata 2 (S2) Magister Komputer di Universitas Sumatera Utara Fakultas IImu Komputer dan Teknologi Informasi. Saat ini berstatus dosen tetap Universitas harapan medan. Penulis dibeberapa jurnal dan Dosen di Universitas Harapan Medan dari tahun 2011.

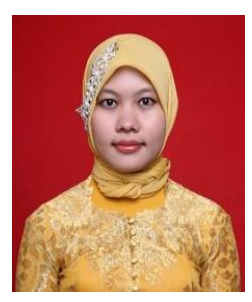

Siti Sundari, ST, M.Kom Lahir di sidodadi Tanggal/bln/tahun 06/12/1987 Pendidikan Strata1 (S1)Program Studi Teknik Informatika di Sekolah Tinggi Teknik Harapan (STTH) Medan dan Strata 2 (S2) Magister Ilmu Komputer Program Studi Ilmu Komputer di Program Pasca sarjana Universitas Putra Indoensia (YPTK) Padang. Penulis dibeberapa jurnal dan Dosen di Universitas Harapan Medan dari tahun 2012. 